\title{
Lateral-torsional buckling of unrestrained steel beams under fire conditions: improvement of EC3 proposal
}

\author{
P.M.M. Vila Real ${ }^{\text {a,* }}$, N. Lopes ${ }^{\text {a }}$, L. Simões da Silva ${ }^{\text {b }}$, J.-M. Franssen ${ }^{\text {c }}$ \\ a Department of Civil Engineering, University of Aveiro, 3810 Aveiro, Portugal \\ ${ }^{\mathrm{b}}$ Department of Civil Engineering, University of Coimbra, 3030-290 Coimbra, Portugal \\ ' Department M\&S, University of Liege, Liege, Belgium
}

Received 2 July 2003; accepted 18 January 2004

Available online 17 June 2004

\begin{abstract}
The final draft of the EN version of part 1.1 of Eurocode 3 has introduced significant changes in the evaluation of the lateral-torsional buckling resistance of unrestrained beams at room temperature that reduce the over-conservative approach of ENV 1993-1-1 in the case of non-uniform bending.

Numerical modelling of the lateral-torsional buckling of steel beams at elevated temperature has shown that the beam design curve from prEN 1993-1-2 is over-conservative for loadings other than uniform bending.

In line with the safety format of the lateral-torsional buckling code provisions for cold design, an alternative proposal for rolled sections or equivalent welded sections subjected to fire is presented in this paper, that addresses the issue of the influence of the loading type on the resistance of the beam, achieving better agreement with the real behaviour while maintaining safety.

(c) 2004 Elsevier Ltd. All rights reserved.
\end{abstract}

Keywords: Steel beam; Lateral-torsional buckling; Fire; Eurocode 3; Numerical modelling

\section{Introduction}

Recently, at the occasion of the conversion of Eurocode 3 from ENV to EN status, the project team introduced significant changes in the evaluation of the lateral-torsional buckling resistance of unrestrained beams at room temperature [1] that reduce the overconservative approach of ENV 1993-1-1 [2] in the case of non-uniform bending.

Also recently, but for opposite reasons, Vila Real and Franssen [3,4] and Vila Real et al. [5] proposed an alternative expression for the lateral-torsional buckling resistance of unrestrained beams under fire loading. This

\footnotetext{
${ }^{*}$ Corresponding author. Tel.: +351-234-370049; fax: +351234-370094.

E-mail address: pvreal@civil.ua.pt (P.M.M. Vila Real).
}

change, already adopted by the project team of part 1.2 of EC3 [6], was triggered by the identification of the unconservative nature of the previous expression [7] for the case of a simply supported beam with fork supports under uniform bending.

Codes of practice are aimed at providing safe, competitive and, as far as possible, simple procedures for the design of structures. Drafting and implementing a consistent set of Structural Eurocodes involving a large number of groups of experts is naturally a recursive task where each part must reflect the scientific advances and design options of all other related parts. Such is the case of Eurocode 3 and, in particular, the need to ensure compatibility and coherence between part 1.1 (general rules and rules for buildings) [1] and part 1.2 (fire design) [6].

It is the objective of the present paper to propose a consistent safety check for the lateral-torsional buckling resistance of beams under fire loading, by adapting the 


\begin{tabular}{|c|c|c|c|}
\hline \multicolumn{4}{|c|}{ Nomenclature } \\
\hline E & Young's modulus & $W_{\mathrm{pl}, y}$ & plastic section modulus in $y$-axis \\
\hline$f_{\mathrm{y}}$ & yield strength & Greeks & \\
\hline$k_{\mathrm{y}, \theta}$ & $\begin{array}{l}\text { reduction factor for the yield strength at } \\
\text { temperature } \theta_{a}\end{array}$ & $\alpha$ & imperfection factor \\
\hline$k_{\mathrm{E}, \theta}$ & $\begin{array}{l}\text { reduction factor for the slope of the linear } \\
\text { elastic range at temperature } \theta_{a}\end{array}$ & $\begin{array}{l}\gamma_{\mathrm{M} 0} \\
\gamma_{\mathrm{M}, \mathrm{fi}}\end{array}$ & $\begin{array}{l}\text { partial safety factor (usually } \gamma_{\mathrm{M} 0}=1.0 \text { ) } \\
\text { partial safety factor for the fire situation }\end{array}$ \\
\hline$M_{\text {SAFIR }}$ & $\begin{array}{l}\text { resistant moment in the fire design situation } \\
\text { given by SAFIR }\end{array}$ & $\bar{\lambda}_{\mathrm{LT}}$ & $\begin{array}{l}\text { non-dimensional slenderness for lateral-tor- } \\
\text { sional bucking at room temperature }\end{array}$ \\
\hline$M_{y, \mathrm{fi}, \mathrm{Ed}}$ & $\begin{array}{l}\text { design bending moment about } y \text {-axis for the } \\
\text { fire design situation }\end{array}$ & $\bar{\lambda}_{\mathrm{LT}, \theta}$ & $\begin{array}{l}\text { non-dimensional slenderness for lateral-tor- } \\
\text { sional buckling at temperature } \theta\end{array}$ \\
\hline$M_{y, \mathrm{fi}, \theta, \mathrm{Rd}}$ & $\begin{array}{l}\text { design moment resistance about } y \text {-axis of a } \\
\text { Class } 1 \text { or } 2 \text { cross-section with a uniform } \\
\text { temperature } \theta_{a}\end{array}$ & $\chi_{\mathrm{LT}, \mathrm{fi}}$ & $\begin{array}{l}\text { reduction factor for lateral-torsional buck- } \\
\text { ling in the fire design situation }\end{array}$ \\
\hline
\end{tabular}

newly proposed methodology for cold design to fire design. This adaptation is subsequently assessed using the specialised finite element code SAFIR [8], which is a finite element code for geometrical and material nonlinear analysis, specially developed at the University of Liege for studying structures subjected to fire.

A three-dimensional (3D) beam element has been used, based on the following formulations and hypotheses:

- Displacement type element in a total co-rotational description.

- Prismatic element.

- The displacement of the node line is described by the displacements of the three nodes of the element, two nodes at each end supporting seven degrees of freedom, three translations, three rotations and the warping amplitude, plus one node at the mid-length supporting one degree of freedom, namely the nonlinear part of the longitudinal displacement.

- The Bernoulli hypothesis is considered, i.e., in bending, plane sections remain plane and perpendicular to the longitudinal axis and no shear deformation is considered.

- No local buckling is taken into account, which is the reason why only Class 1 and Class 2 sections can be used [6].

- The strains are small (von Kármán hypothesis), i.e.,

$\frac{1}{2} \frac{\partial u}{\partial x} \ll 1$

where $u$ is the longitudinal displacement and $x$ is the longitudinal co-ordinate.

- The angles between the deformed longitudinal axis and the undeformed but translated longitudinal axis are small, i.e.,

$\sin \varphi \cong \varphi \quad$ and $\quad \cos \varphi \cong 1$ where $\varphi$ is the angle between the arc and the chord of the translated beam finite element.

- The longitudinal integrations are numerically calculated using Gauss' method.

- The cross-section is discretised by means of triangular or quadrilateral fibres. At every longitudinal point of integration, all variables, such as temperature, strain, stress, etc., are uniform in each fibre.

- The tangent stiffness matrix is evaluated at each iteration of the convergence process (pure NewtonRaphson method).

- Residual stresses are considered by means of initial and constant strains [9].

- The material behaviour in case of strain unloading is elastic, with the elastic modulus equal to the Young's modulus at the origin of the stress-strain curve. In the same cross-section, some fibres that have yielded may therefore exhibit a decreased tangent modulus because they are still on the loading branch, whereas, at the same time, some other fibres behave elastically. The plastic strain is presumed not to be affected by a change in temperature [10].

- The elastic torsional stiffness at $20{ }^{\circ} \mathrm{C}$ that is calculated by the code has been adapted in an interactive process in order to reflect the decrease of material stiffness for the analysed temperatures [11], multiplying the torsional stiffness at $20{ }^{\circ} \mathrm{C}$ by the reduction factor of the modulus of elasticity, $k_{\mathrm{E}, \theta}[6]$ corresponding to those temperatures.

\section{Case study}

A simply supported beam with fork supports was chosen to explore the validity of the beam safety verifications, as shown in Fig. 1. Regarding the bending moment variation along the member length, three values, $(-1,0,1)$, of the $\psi$ ratio (see Fig. 1 ) have been 


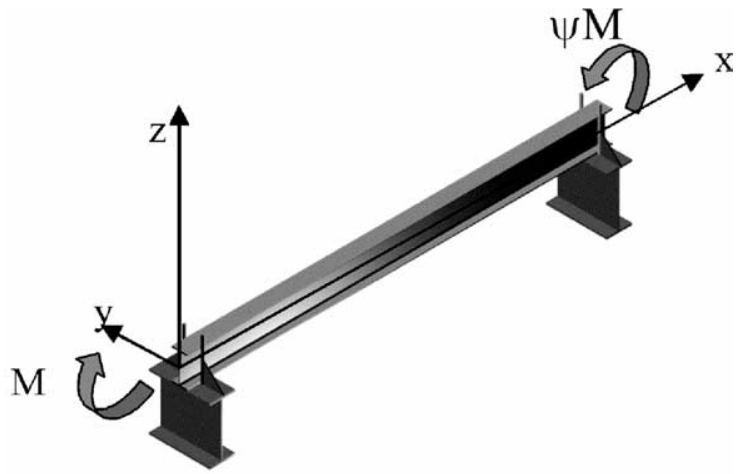

Fig. 1. Simply supported beam with uniform bending.

investigated as well as a uniformly distributed load or a mid-span concentrated load. An IPE 220 steel section of grade $\mathrm{S} 235$ was used.

Uniform temperature in the cross-section has been used so that comparison between the numerical results and the eurocodes could be made. In this paper the temperatures used were 400, 500, 600 and $700{ }^{\circ} \mathrm{C}$, deemed to adequately represent the majority of practical situations.

A lateral geometric imperfection given by the following expression was considered:

$y(x)=\frac{l}{1000} \sin \left(\frac{\pi x}{l}\right)$

An initial rotation around the longitudinal axis with a maximum value of $l / 1000 \mathrm{rad}$ at mid-span was also introduced.

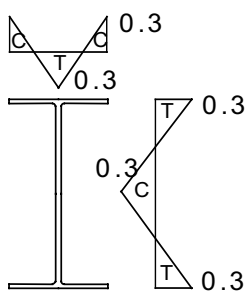

Fig. 2. Residual stresses: $\mathrm{C}$-compression; $\mathrm{T}$ - tension.

Finally, the residual stresses adopted are constant across the thickness of the web and flanges. A triangular distribution as shown in Fig. 2, with a maximum value of $0.3 \times 235 \mathrm{MPa}$, for the $\mathrm{S} 235$ steel has been used [12].

\section{Parametric evaluation of the lateral-torsional buckling code provisions of Eurocode 3}

In order to provide a basis for the subsequent parametric study, the code provisions for the lateral-torsional buckling of beams at room and high temperatures are described below in detail.

\subsection{ENV 1993-1-1/prEN 1993-1-1 proposals at room temperature}

At room temperature, beams with cross-sectional Classes 1 and 2 subjected to major-axis bending, must generically satisfy the following relation:

Table 1

Comparison between ENV 1993-1-1 and prEN 1993-1-1 formulae

\begin{tabular}{|c|c|c|c|}
\hline & \multirow{2}{*}{$\begin{array}{l}\text { ENV 1993-1-1 } \\
(5.5 .3)\end{array}$} & \multicolumn{2}{|l|}{ prEN 1993-1-1 } \\
\hline & & General Case (6.3.2.2) & Special Case (6.3.2.3) \\
\hline$\chi_{\mathrm{LT}}$ & $\chi_{\mathrm{LT}}=\frac{}{\phi_{\mathrm{LT}}+}$ & $\overline{\overline{l_{\mathrm{LT}}^{2}}}, 1$ & $\begin{array}{l}\min \text { of } \chi_{\mathrm{LT}}=\frac{1}{\phi_{\mathrm{LT}}+\sqrt{\phi_{\mathrm{LT}}^{2}-\beta \bar{\lambda}_{\mathrm{LT}}^{2}}}, 1, \\
\chi_{\mathrm{LT}}=\frac{1}{\bar{\lambda}_{\mathrm{LT}}^{2}}\end{array}$ \\
\hline$\chi_{\mathrm{LT}, \bmod }$ & & & $\chi_{\mathrm{LT}, \bmod }=\frac{1}{f}$ \\
\hline$f$ & & & $\min$ of $f=1-0.5\left(1-k_{\mathrm{c}}\right)\left[1-2\left(\bar{\lambda}_{\mathrm{LT}}-0.8\right)^{2}\right], 1$ \\
\hline \multirow[t]{2}{*}{$\phi_{\mathrm{LT}}$} & $\phi_{\mathrm{LT}}=\frac{1}{2}[1+\alpha$ & $\left.0.2)+\bar{\lambda}_{\mathrm{LT}}^{2}\right]$ & $\phi_{\mathrm{LT}}=\frac{1}{2}\left[1+\alpha_{\mathrm{LT}}\left(\bar{\lambda}_{\mathrm{LT}}-\bar{\lambda}_{\mathrm{LT}, 0}\right)+\beta \bar{\lambda}_{\mathrm{LT}}^{2}\right]$ \\
\hline & Dispensing con & & \\
\hline $\bar{\lambda}_{\mathrm{LT}}$ & $\overline{0.4}$ & 0.2 & 0.4 \\
\hline$M_{\mathrm{Ed}} / M_{\mathrm{cr}}$ & - & 0.04 & 0.16 \\
\hline
\end{tabular}




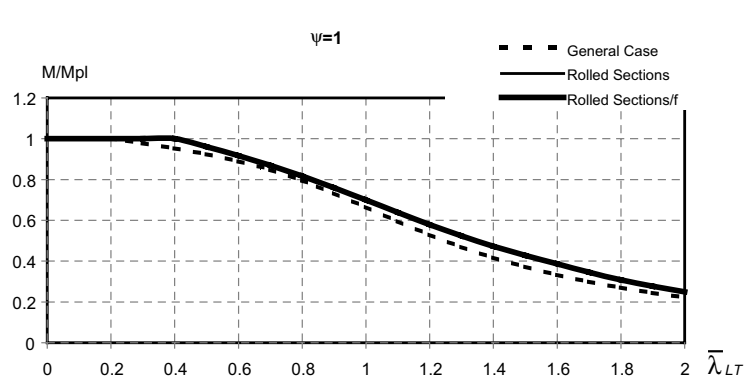

(a)

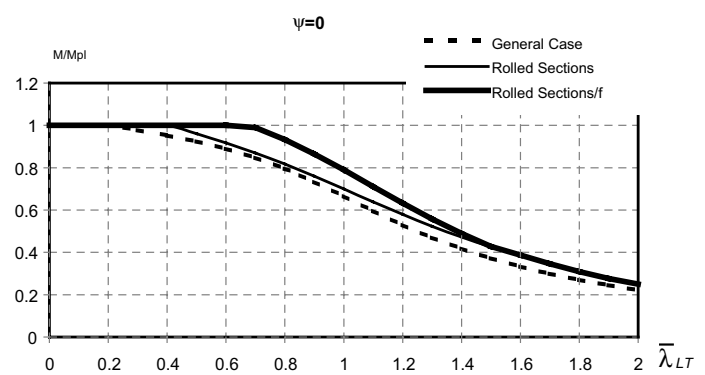

(b)

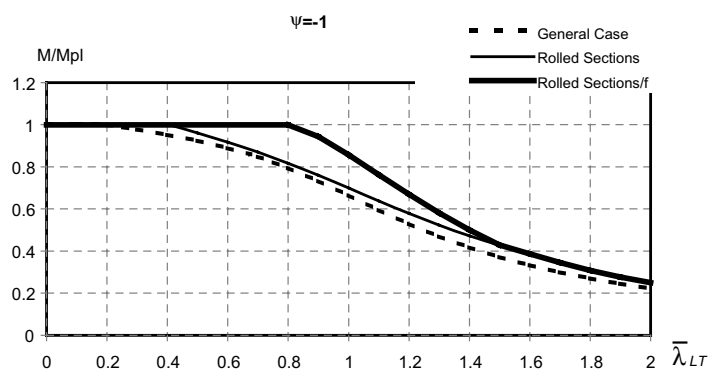

(c)

Fig. 3. Beam design curve for the three methods of the prEN 1993-1-1. (a) $\psi=1$; (b) $\psi=0$ and (c) $\psi=-1$.

Table 2

Correction factors $k_{\mathrm{c}}[1]$

\begin{tabular}{|c|c|}
\hline Moment distribution & $\begin{array}{l}\text { Class } 1,2,3 \text { sections } \\
k_{\mathrm{c}}\end{array}$ \\
\hline & 1.0 \\
\hline \multicolumn{2}{|l|}{$\psi=1$} \\
\hline$M_{\odot}$ & 1 \\
\hline$\psi_{M}$ & $\overline{1.33-0.33 \psi}$ \\
\hline \multicolumn{2}{|l|}{$-1 \leqslant \psi \leqslant 1$} \\
\hline & 0.94 \\
\hline & 0.86 \\
\hline
\end{tabular}

$M_{\mathrm{b}, \mathrm{Rd}}=\chi_{\mathrm{LT}} W_{\mathrm{pl}, y} \frac{f_{\mathrm{y}}}{\gamma_{\mathrm{M} 1}}$

where $f_{\mathrm{y}}$ denotes the yield stress of steel, $\gamma_{\mathrm{M} 1}$ the appropriate partial safety factor, $W_{\mathrm{pl}, y}$ the plastic modulus of the section about the major axis and $\chi_{\mathrm{LT}}$ represents the reduction factor for lateral-torsional buckling and depends on the so-called non-dimensional slenderness, $\bar{\lambda}_{\mathrm{LT}}$, given by

$\bar{\lambda}_{\mathrm{LT}}=\sqrt{\frac{W_{\mathrm{pl}, y} f_{\mathrm{y}}}{M_{\mathrm{cr}}}}$

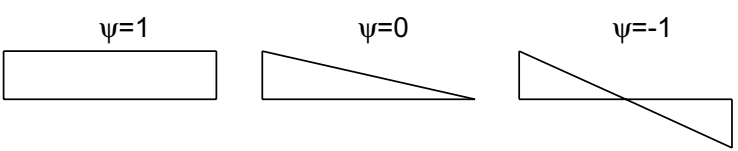

Fig. 4. Studied bending diagrams.

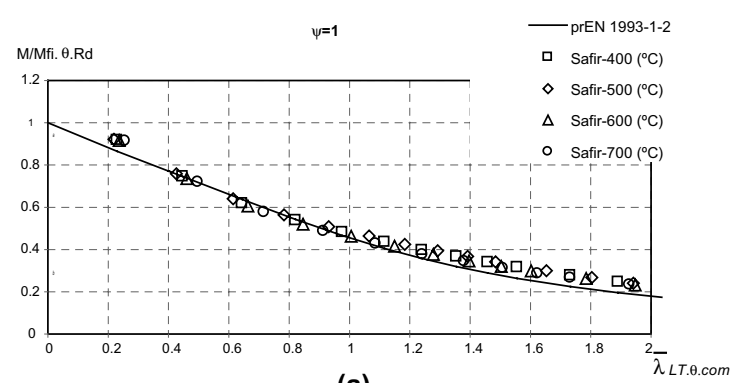

(a)

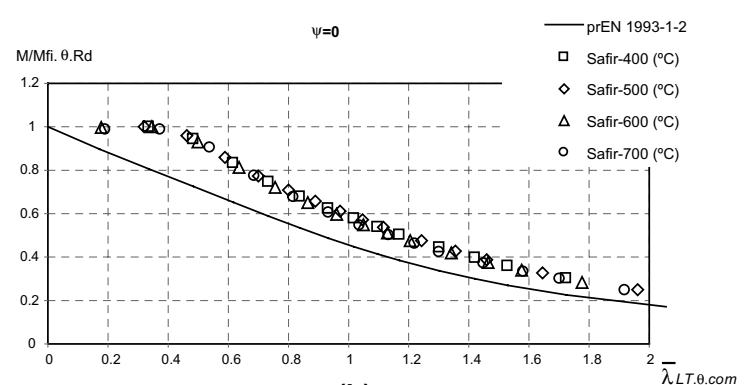

(b)

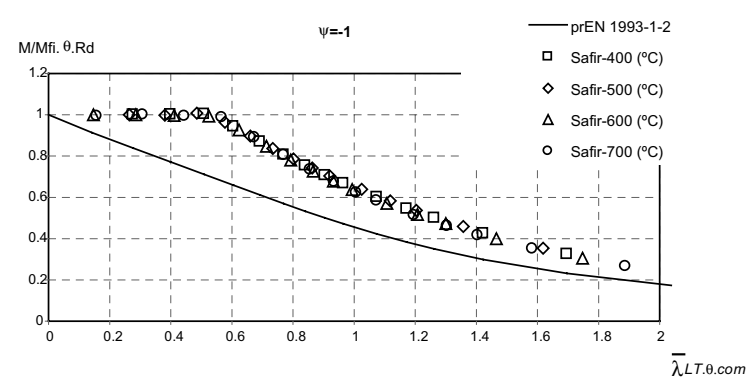

(c)

Fig. 5. Beam design curve from the prEN 1993-1-2, for different values of $\psi$. (a) $\psi=1$; (b) $\psi=0$ and (c) $\psi=-1$. 
where $M_{\mathrm{cr}}$ denotes the elastic critical moment for lateraltorsional buckling, calculated on the basis of the gross cross-sectional properties and taking into account the loading conditions, the real moment distribution and the lateral restraints.

In both the ENV and EN versions of part 1.1 of Eurocode 3 , the reduction factor $\chi_{\mathrm{LT}}$ is formally based on the Rondal-Maquoi formula, detailed derivations being found in [13]. In contrast to the ENV implementation, that presented a single option for the evaluation of the lateral-torsional buckling reduction factor $\chi_{\mathrm{LT}}$, summarized in Table 1, the EN version allows two alternatives, also summarized in Table 1 and explained below, where $\alpha_{\mathrm{LT}}$ denotes the imperfection factors for lateral-torsional buckling curves.

The first method described at the prEN 1993-1-1, denoted "General Case" in Fig. 3, basically reproduces the ENV proposal with a modified level of imperfection factors, $\alpha_{\mathrm{LT}}$, and more strict conditions to neglect the LTB check, see Table 1.

A careful examination of the general procedure discussed above quickly reveals that the influence of the bending moment diagram on the LTB resistance of the beam only appears indirectly through the value of the elastic critical moment. This assumption is over-conservative, as can be easily seen by comparing with, for example, the Australian code of practice, or the theoretical results of Trahair and Bradford [14].

The second method, denoted "Rolled Sections" in Fig. 3, applicable for the particular case of rolled sections or equivalent welded sections, yields greater LTB resistance, the detailed procedure for this method being also shown in Table 1. It is noted that two modifying

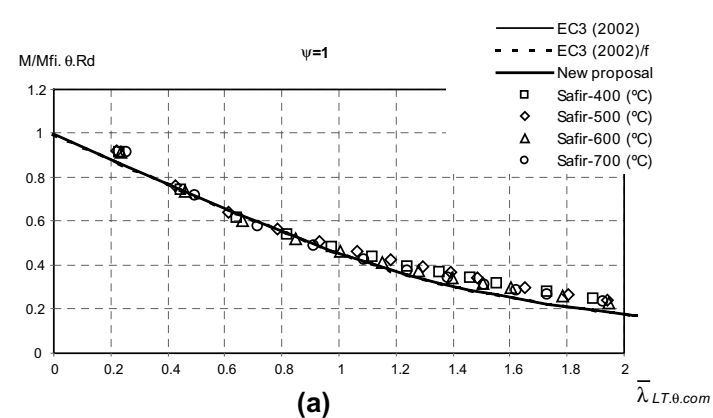

(a)

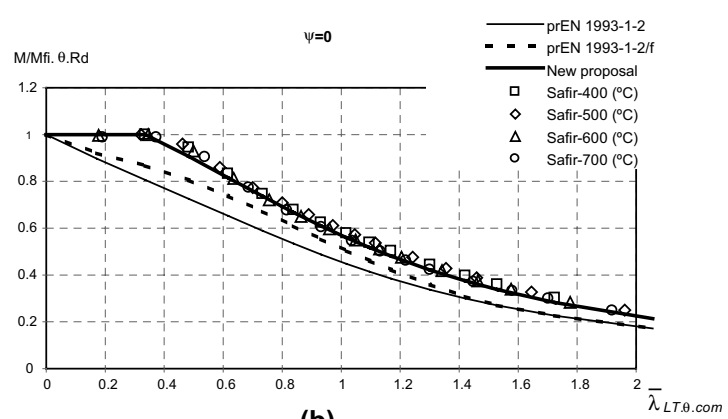

(b)

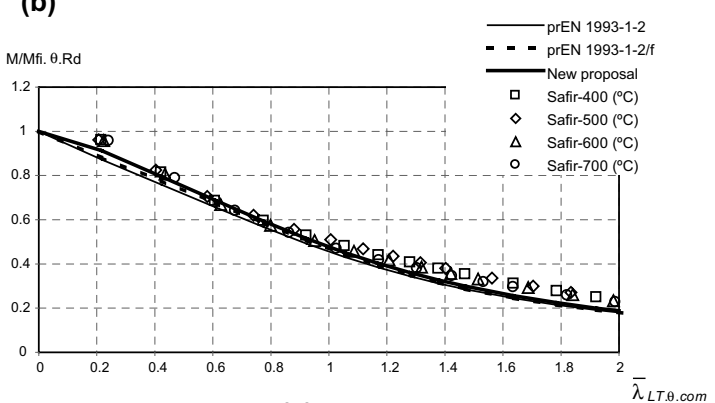

(e)

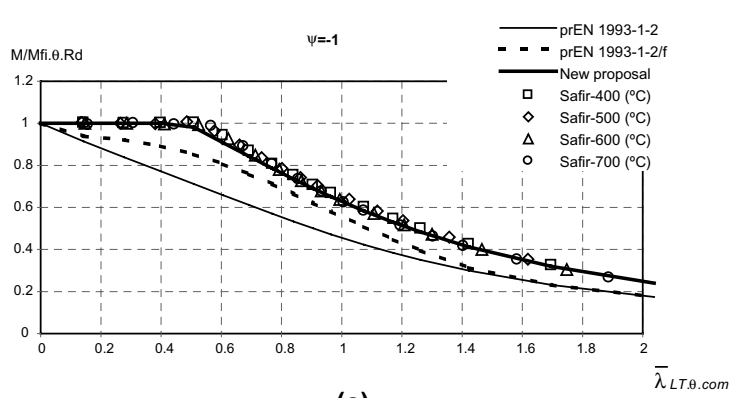

(c)

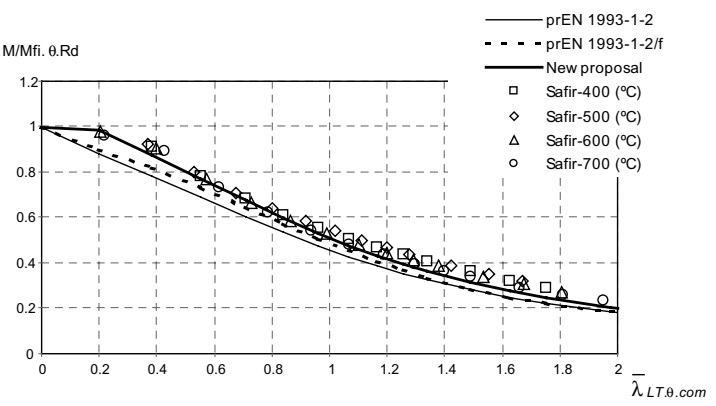

(d)

Fig. 6. Beam design curve from the prEN 1993-1-2, the reduction factor modified according to prEN 1993-1-1, denoted by "prEN 1993-1-2/f" and the new proposal. (a) $\psi=1$; (b) $\psi=0$; (c) $\psi=-1$; (d) case B and (e) case C. 
parameters, $\bar{\lambda}_{\mathrm{LT}, 0}$ and $\beta$ are introduced, that should be taken as:

$\lambda_{\mathrm{LT}, 0}=0.4 \quad$ (maximum value)

$\beta=0.75 \quad$ (minimum value)

and the dispensing conditions for LTB check are relaxed as shown in Table 1 .

Additionally, for the second method, and to address the issue of the influence of the bending moment diagram, the use of a modified reduction factor, $\chi_{\mathrm{LT}, \text { mod }}$ (see Table 1), is allowed, that depends on the moment distribution correction factor, $k_{\mathrm{c}}$, illustrated in Table 2 for some common loading cases. This third method is denoted "Rolled Sections/f" in Fig. 3.

Fig. 3 shows, for the three values of the $\psi$ ratio, $-1,0$, 1 shown in Fig. 4, the beam design curve for lateraltorsional buckling for the three methods presented at the prEN 1993-1-1 [1].

\section{2. prEN 1993-1-2 Proposals at high temperatures}

According to this proposal, the design buckling resistance moment of a laterally unrestrained beam with a Class 1 or 2 cross-section type, is obtained as follows:

$M_{\mathrm{b}, \mathrm{fi}, t, \mathrm{Rd}}=\chi_{\mathrm{LT}, \mathrm{fi}} W_{\mathrm{pl}, y} k_{\mathrm{y}, \theta, \mathrm{com}} f_{\mathrm{y}} \frac{1}{\gamma_{\mathrm{M}, \mathrm{fi}}}$

where $\chi_{\mathrm{LT}, \mathrm{fi}}$, is given by

$\chi_{\mathrm{LT}, \mathrm{fi}}=\frac{1}{\phi_{\mathrm{LT}, \theta, \mathrm{com}}+\sqrt{\left[\phi_{\mathrm{LT}, \theta, \mathrm{com}}\right]^{2}-\left[\bar{\lambda}_{\mathrm{LT}, \theta, \mathrm{com}}\right]^{2}}}$

with

$\phi_{\mathrm{LT}, \theta, \mathrm{com}}=\frac{1}{2}\left[1+\alpha \bar{\lambda}_{\mathrm{LT}, \theta, \mathrm{com}}+\left(\bar{\lambda}_{\mathrm{LT}, \theta, \mathrm{com}}\right)^{2}\right]$

and $k_{\mathrm{y}, \theta, \mathrm{com}}$ is the reduction factor for the yield strength at the maximum temperature in the compression flange $\theta_{a, \text { com }}$, reached at time $t ; \gamma_{\mathrm{M} . \mathrm{fi}}$ is the partial safety factor for the fire situation (usually $\gamma_{\mathrm{M} . \mathrm{fi}}=1$ ).

The non-dimensional slenderness $\bar{\lambda}_{\mathrm{LT}, \theta, \text { com }}$ (or $\bar{\lambda}_{\mathrm{LT}, \mathrm{fi}}$, if the temperature field in the cross-section is uniform) given by

$\bar{\lambda}_{\mathrm{LT}, \theta, \mathrm{com}}=\bar{\lambda}_{\mathrm{LT}, \mathrm{fi}}=\bar{\lambda}_{\mathrm{LT}} \sqrt{\frac{k_{\mathrm{y}, \theta \text { com }}}{k_{\mathrm{E}, \theta, \mathrm{com}}}}$

where $\bar{\lambda}_{\mathrm{LT}}$ is the non-dimensional slenderness at room temperature given by Eq. (3) (for Class 1 or 2 crosssections); $k_{\mathrm{E}, \theta, \text { com }}$ is the reduction factor for the slope of the linear elastic range at the maximum steel temperature reached at time $t$.

The imperfection factor $\alpha$, in this proposal, is a function of the steel grade and is given by:

$\alpha=0.65 \sqrt{235 / f_{\mathrm{y}}}$
As shown in Fig. 5, for the three values of the $\psi$ ratio, $-1,0,1$ shown in Fig. 4, this formulae from the prEN 1993-1-2, lead to over-conservative results when compared to numerical results for the case of non-uniform bending.

\subsection{Improved formulae at high temperature. A new proposal}

Fig. 5 clearly highlights that there is scope for improvement in the evaluation of the lateral-torsional buckling resistance of beams. Based on the prEN 1993-1-1 version of the Eurocode 3 it seems reasonable to propose, at high temperature, a second method, more accurate and less conservative that improves the results of Fig. 5.

Given that the main factor responsible for the overconservative nature of the lateral-torsional buckling resistance at high temperatures was linked to the loading type, the new proposal also adopts a modified reduction factor for lateral-torsional buckling, $\chi_{\mathrm{LT}, \text { fi.mod }}$, given by

Table 3

Correction factors $k_{\mathrm{c}}$ for the new proposal

\begin{tabular}{|c|c|c|}
\hline & Moment distribution & $\begin{array}{l}\text { Class } 1,2,3 \text { sections } \\
k_{\mathrm{c}}\end{array}$ \\
\hline A & & $\begin{array}{l}0.6+0.3 \psi+0.15 \psi^{2} \\
\text { but } k_{\mathrm{c}} \leqslant 1\end{array}$ \\
\hline & $-1 \leqslant \psi \leqslant 1$ & \\
\hline B & & 0.79 \\
\hline $\mathrm{C}$ & & 0.91 \\
\hline
\end{tabular}

Note: for others bending diagrams $k_{\mathrm{c}}=1$.

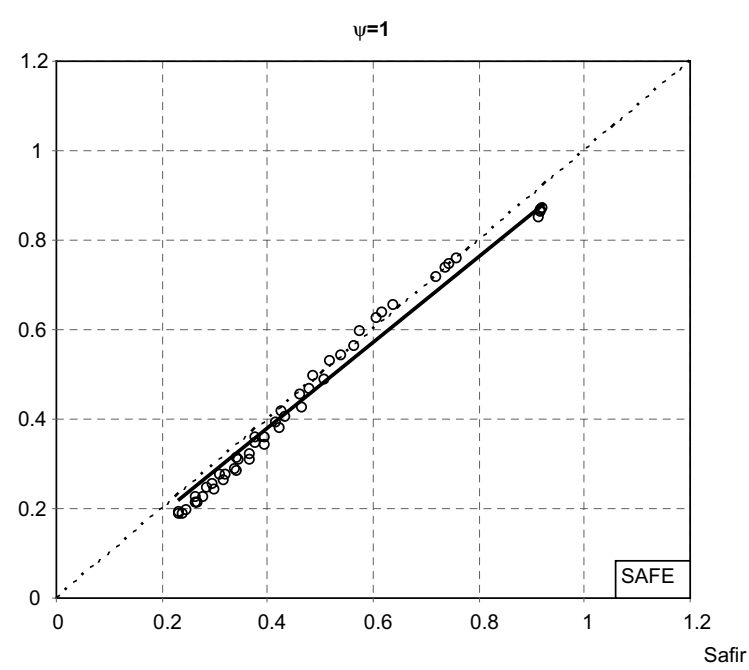

Fig. 7. Results for $\psi=1$ and the three studied methods: "prEN 1993-1-2", "prEN 1993-1-2/f" and "New proposal" (all coincident). 
$\chi_{\mathrm{LT}, \mathrm{fi}, \mathrm{mod}}=\frac{\chi_{\mathrm{LT}, \mathrm{fi}}}{f}$ but $\chi_{\mathrm{LT}, \mathrm{fi}, \mathrm{mod}} \leqslant 1$

where $f$ depends on the loading type.

prEN 1993-1-2

$\psi=0$

(a)

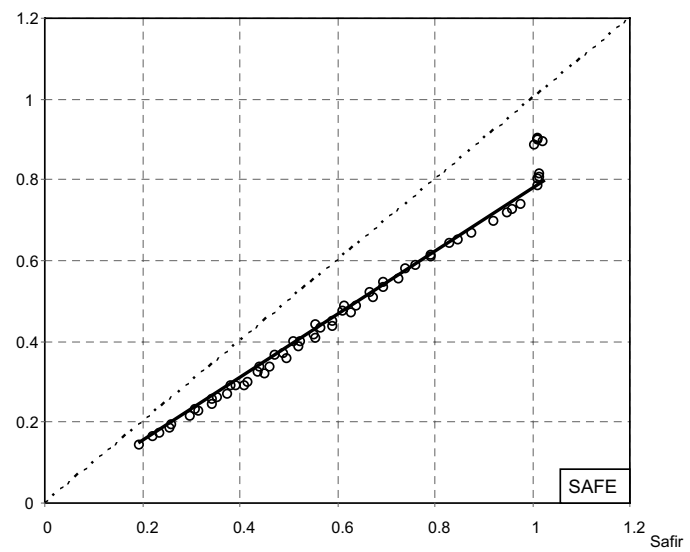

(b)

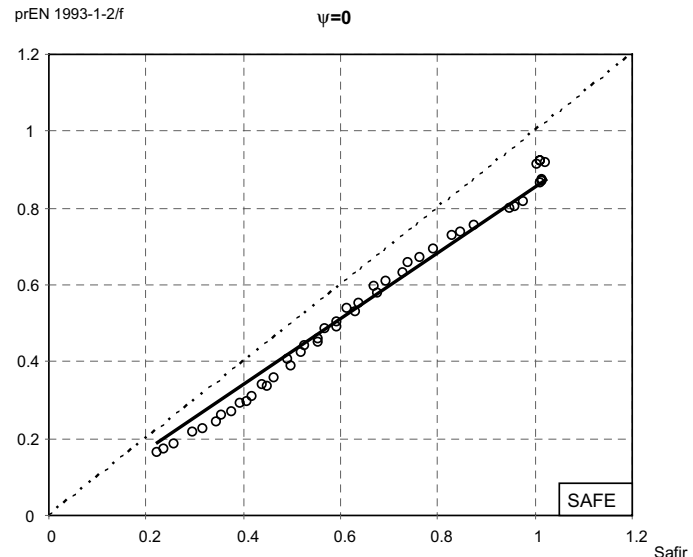

(c)

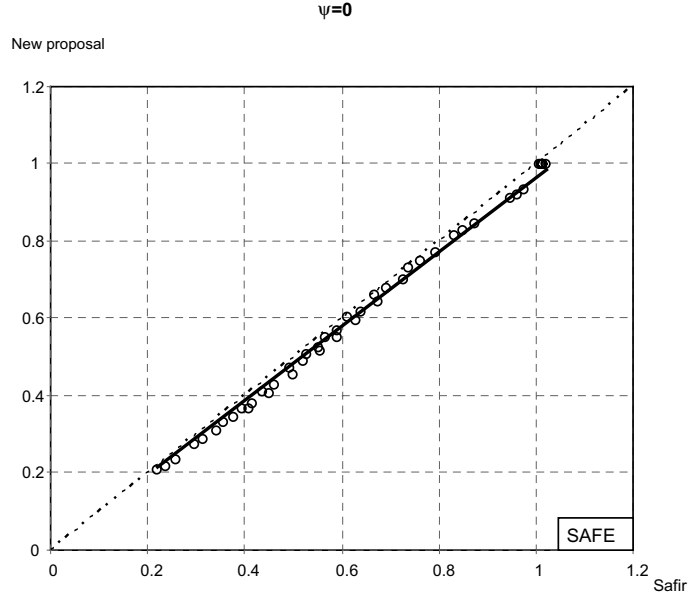

Fig. 8. Results for $\psi=0$. (a) "prEN 1993-1-2"; (b) "prEN 1993-1-2/f" and (c) "New proposal".
Initially, the adequacy of part 1.1 proposals for $f$ and $k_{\mathrm{c}}$ (see Tables 1 and 2 ) were tested. The results, denoted as "prEN 1993-1-2/f" in Fig. 6, are better and closer to the numerical values but still remain conservative. Consequently, in order to have a better approximation,

prEN1993-1-2 $\quad \psi=-1$

(a)

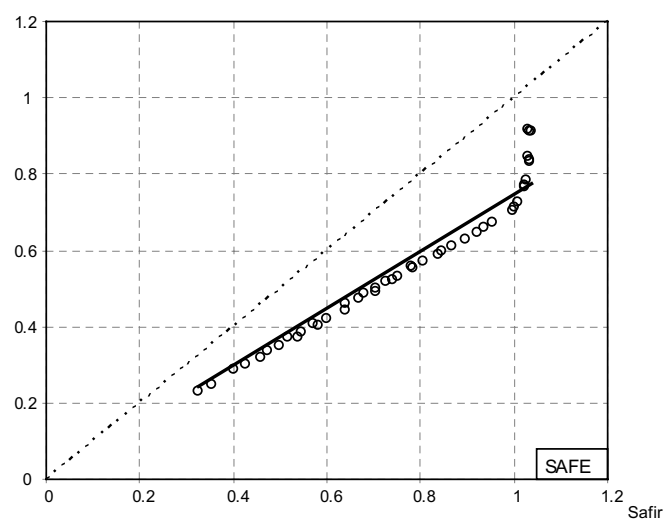

prEN 1993-1-2/f $\quad \psi=-1$

(b)

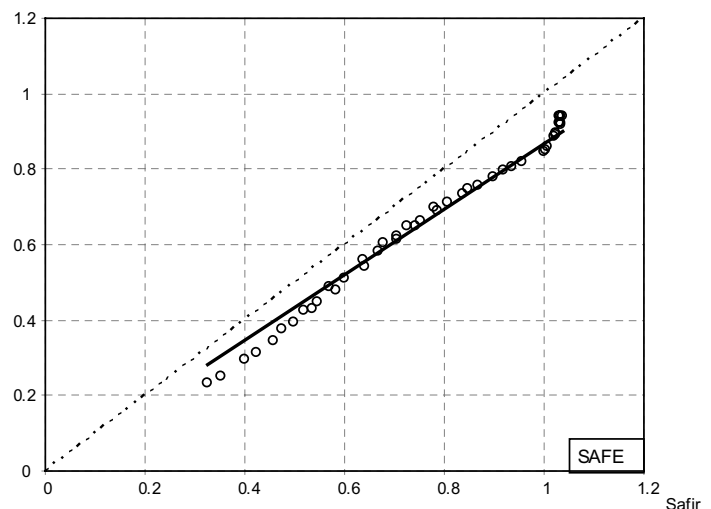

New proposal $\quad \psi=-1$

(c)

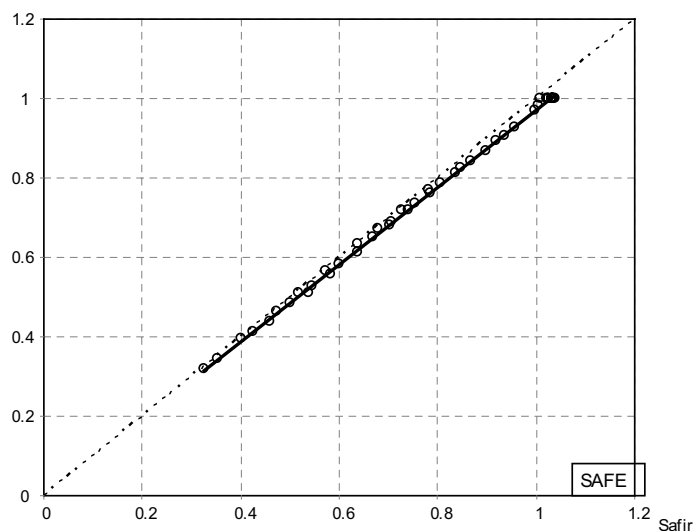

Fig. 9. Results for $\psi=-1$. (a) "prEN 1993-1-2"; (b) “prEN 1993-1-2/f" and (c) "New proposal". 
taking into account the moment distribution between the lateral restraints of members, new coefficients for $f$ and $k_{\mathrm{c}}$ were adjusted, given by the following equation

$f=1-0.5\left(1-k_{\mathrm{c}}\right)$

where $k_{\mathrm{c}}$ is a correction factor according to Table 3 .

As it can be seen in Fig. 6, this new proposal shows a very good agreement with the numerical results. This figure illustrates the results for several values of ratio $\psi$ of case A and for the cases B and C (see Table 3).

To highlight the safety of the various proposals, Figs. 7-9 compare the numerical results with the three proposals (results from the prEN 1993-1-2, the results obtained using factor $f$ from prEN 1993-1-1 and finally with the new proposal) using regression lines (Fig. 8).

The regression line in Figs. 7-9 is much more close to the ideal dashed line for the new proposal. From these figures it is clear that the new proposal is safe and at the same time less conservative than the other two studied methods.

\section{Conclusions}

A new proposal for the lateral-torsional buckling resistance of beams under fire loading has been proposed. It was adapted from the newly proposed methodology for cold design from the later version of prEN 1993-1-1 [1] as an alternative method for rolled sections or equivalent welded sections. The proposed method approximates more closely the real behaviour of unrestrained steel beams under fire conditions, while still remaining on the safe side. Although the numerical study presented here was limited to a single section size (IPE 220) and steel class (S235), the conclusions are valid for a wider range of cross-section sizes and types. In fact, according to the different cases presented in part 1-1 of EC3, profiles with $h / b>2$ and $h / b<2$ were also tested, namely IPE 500 and HEA 500, yielding the same trends. This extrapolation is further confirmed by previous parametric studies for different steel sections and steel grades performed for uniform bending $[4,15]$ concluded that the behaviour was similar for all the studied profiles.

It is worth noting that experimental confirmation resulting from well instrumented and carefully carried out experimental tests to verify whether the present proposal can actually reproduce the test would be welcome. It is nevertheless noted that there is a low probability for the two structural imperfections, residual stresses and initial imperfection, occurring simultaneously in a test, with the high amplitude assumed here in the numerical simulations.

\section{References}

[1] Eurocode 3, Design of Steel Structures-part 1-1. General rules and rules for buildings. prEN 1993-1-1:2003, Stage 34 Draft, European Committee for Standardisation, Brussels, Belgium, 2003.

[2] Eurocode 3, Design of Steel Structures-part 1-1. General rules and rules for buildings. ENV 1993-1-1, Commission of the European Communities, Brussels, Belgium, 1992.

[3] Vila Real PMM, Franssen J-M. Lateral buckling of steel I beams under fire conditions - comparison between the EUROCODE 3 and the SAFIR code. Internal report no. 99/02, Institute of Civil Engineering-Service Ponts et Charpents - of the University of Liege 1999.

[4] Vila Real PMM, Franssen J-M. Numerical modelling of lateral buckling of steel I beams under fire conditionscomparison with Eurocode 3. J Fire Protect Eng, USA 2001;11(2):112-28.

[5] Vila Real PMM, Piloto PAG, Franssen J-M. A new proposal of a simple model for the lateral-torsional buckling of unrestrained steel I-beams in case of fire: experimental and numerical validation. J Construct Steel Res 2003;59/2:179-99.

[6] EUROCODE 3, Design of steel structures-part 1-2. General rules-structural fire design. Draft prEN 1993-12:20xx, Stage 34, European Committee for Standardisation, Brussels, Belgium, February 2002.

[7] EUROCODE 3, Design of steel structures - part 1-2. General rules-structural fire design. ENV 1993-1-2, European Committee for Standardisation, Brussels, Belgium, 1995.

[8] Franssen J-M, SAFIR. A thermal/structural program modeling structures under fire. In: Proceedings of the NASCC Conference, American Institute for Steel Construction, Baltimore, April 2003.

[9] Franssen J-M. Modelling of the residual stresses influence in the behaviour of hot-rolled profiles under fire conditions. Construct Métall 1989;3:35-42 [in French].

[10] Franssen JM. The unloading of building materials submitted to fire. Fire Safety J 1990;16:213-27.

[11] Souza V, Franssen J-M. Lateral buckling of steel I beams at elevated temperature - comparison between the modelling with beam and shell elements. In: Lamas A, Simões da Silva L, editors. Proceedings of the 3rd European Conference on Steel Structures. ISBN: 972-98376-3-5, Coimbra, Univ. de Coimbra, 2002. p. 1479-88.

[12] ECCS-EUROPEAN CONVENTION FOR CONSTRUCTIONAL STEELWORK, Technical Committee 8-Structural Stability, Technical Working Group 8.2System. Ultimate limit state calculation of sway frames with rigid joints, 1st ed., 1984.

[13] Maquoi R, Rondal J. Mise en equation des nouvelles courbes Européennes de flambement. Construct Métall 1978;1:17-29 [in French].

[14] Trahair NS, Bradford MA. The behaviour and design of steel structure to AS 4100, 3rd ed. E\&FN SPON, Australian, 1998.

[15] Cazeli R, Vila Real PMM, Silva VP, Piloto PAG. Numerical modelling of the lateral-torsional buckling of steel I-beam under fire conditions. A contribution to validate a new proposal for part 1.2 of the Eurocode 3. In: I Congresso Internacional da Construção Metálica-I CICOM, São Paulo, Brasil, 2001 [in Portuguese]. 